\title{
Automated sequence analysis of atmospheric oxidation pathways: SEQUENCE version 1.0
}

\author{
T. M. Butler \\ Max Planck Institute for Chemistry, Mainz, Germany \\ Received: 8 July 2009 - Published in Geosci. Model Dev. Discuss.: 17 July 2009 \\ Revised: 15 September 2009 - Accepted: 16 September 2009 - Published: 12 October 2009
}

\begin{abstract}
An algorithm for the sequential analysis of the atmospheric oxidation of chemical species using output from a photochemical model is presented. Starting at a "root species", the algorithm traverses all possible reaction sequences which consume this species, and lead, via intermediate products, to final products. The algorithm keeps track of the effects of all of these reactions on their respective reactants and products. Upon completion, the algorithm has built a detailed picture of the effects of the oxidation of the root species on its chemical surroundings. The output of the algorithm can be used to determine product yields, radical recycling fractions, and ozone production potentials of arbitrary chemical species.
\end{abstract}

\section{Introduction}

The chemistry of reactive trace gasses in the atmosphere of the Earth is a highly complex, nonlinear system. The many thousands of volatile organic compounds (VOC) in the troposphere are generally removed by initial attack from the hydroxyl radical $(\mathrm{OH})$, which is formed primarily by photolysis of ozone $\left(\mathrm{O}_{3}\right)$ and subsequent reaction of an excited oxygen atom $\left(\mathrm{O}\left({ }^{1} \mathrm{D}\right)\right)$ with water vapour. The resulting partially oxidised species may be deposited to surfaces, condense into the aerosol phase, or undergo further reactions until they ultimately form unreactive carbon dioxide $\left(\mathrm{CO}_{2}\right)$. This series of further reactions can involve photolysis steps, further loss and/or regeneration of $\mathrm{OH}$ and hydroperoxy radicals $\left(\mathrm{HO}_{2}\right)$, and conversion of nitric oxide (NO) to nitrogen dioxide $\left(\mathrm{NO}_{2}\right)$. The conversion of $\mathrm{NO}$ to $\mathrm{NO}_{2}$ leads subsequently via photolysis of $\mathrm{NO}_{2}$ to the production of $\mathrm{O}_{3}$, which in turn influences the atmospheric radical budget, acts

Correspondence to: T. M. Butler

(tim.butler@mpic.de) as greenhouse gas, and is an important component of photochemical smog.

For decades, numerical models of this system have been used in order to improve our understanding of these processes. Unfortunately these models are often so complex that it can be difficult to understand why they produce the results they do; analysis of the output of atmospheric chemical models remains challenging. Lehmann (2004) describes an algorithm for the automatic determination of dominant pathways in chemical systems. The algorithm of Lehmann (2004) can detect cyclic sequences which yield net production or loss of a species of interest, and as such is especially well suited to the discovery of catalytic cycles of ozone depletion in the stratosphere.

A different approach has been used for the analysis of the effects of specific chemical species on their environment during their degradation, for example the calculation of total ozone yields due to the oxidation of individual VOC. Methane $\left(\mathrm{CH}_{4}\right)$, the simplest and longest lived VOC in the atmosphere, can contribute to tropospheric ozone formation far away from its source regions. The reactions involved in the $\mathrm{OH}$-initiated oxidation of $\mathrm{CH}_{4}$ are shown in Table 1. After the initial attack by $\mathrm{OH}$ and subsequent formation of the methyl peroxy radical (Reaction R1), the peroxy radical may react in seven different ways (R2-R9), some of which ultimately lead to production of $\mathrm{NO}_{2}$, and some of which do not. The products of this second step may themselves be oxidised via a number of different pathways. Each of these possibilities has a different impact on the atmospheric budgets of radicals and $\mathrm{NO}_{\mathrm{x}}$ (collectively $\mathrm{NO}$ and $\mathrm{NO}_{2}$ are known as $\mathrm{NO}_{\mathrm{x}}$ ), and therefore also on the amount of ozone formed.

In order to analyse the effects of methane oxidation on atmospheric chemistry, Johnston and Kinnison (1998), building on earlier work done by Crutzen (1973), identified 34 possible reaction sequences by which $\mathrm{CH}_{4}$ may degrade to carbon monoxide (CO), and derived analytic equations for the combined effect of all of these sequences of $\mathrm{CH}_{4}$

Published by Copernicus Publications on behalf of the European Geosciences Union. 
Table 1. Listing of reactions involved in oxidation of $\mathrm{CH}_{4}$.

\begin{tabular}{|c|c|c|c|}
\hline $\mathrm{CH}_{4}+\mathrm{OH}$ & $\longrightarrow$ & $\mathrm{CH}_{3} \mathrm{O}_{2}$ & $\mathrm{R} 1$ \\
\hline $\mathrm{CH}_{3} \mathrm{O}_{2}+\mathrm{NO}$ & $\longrightarrow$ & $\mathrm{CH}_{3} \mathrm{O}+\mathrm{NO}_{2}$ & $\mathrm{R} 2$ \\
\hline $\mathrm{CH}_{3} \mathrm{O}_{2}+\mathrm{NO}$ & $\longrightarrow$ & $\mathrm{CH}_{3} \mathrm{NO}_{3}$ & R3 \\
\hline $\mathrm{CH}_{3} \mathrm{O}_{2}+\mathrm{NO}_{3}$ & $\longrightarrow$ & $\mathrm{CH}_{3} \mathrm{O}+\mathrm{NO}_{2}$ & R4 \\
\hline $\mathrm{CH}_{3} \mathrm{O}_{2}+\mathrm{HO}_{2}$ & $\longrightarrow$ & $\mathrm{CH}_{3} \mathrm{OOH}$ & R5 \\
\hline $\mathrm{CH}_{3} \mathrm{O}_{2}\left(+\mathrm{RO}_{2}\right)$ & $\longrightarrow$ & $\mathrm{CH}_{3} \mathrm{O}$ & R6 \\
\hline $\mathrm{CH}_{3} \mathrm{O}_{2}\left(+\mathrm{RO}_{2}\right)$ & $\longrightarrow$ & $\mathrm{HCHO}$ & R7 \\
\hline $\mathrm{CH}_{3} \mathrm{O}_{2}\left(+\mathrm{RO}_{2}\right)$ & $\longrightarrow$ & $\mathrm{CH}_{3} \mathrm{OH}$ & $\mathrm{R} 8$ \\
\hline $\mathrm{CH}_{3} \mathrm{O}_{2}+\mathrm{NO}_{2}$ & $\longrightarrow$ & $\mathrm{CH}_{3} \mathrm{O}_{2} \mathrm{NO}_{2}$ & R9 \\
\hline $\mathrm{CH}_{3} \mathrm{O}_{2} \mathrm{NO}_{2}$ & $\longrightarrow$ & $\mathrm{CH}_{3} \mathrm{O}_{2}+\mathrm{NO}_{2}$ & $\mathrm{R} 10$ \\
\hline $\mathrm{CH}_{3} \mathrm{O}$ & $\longrightarrow$ & $\mathrm{HCHO}+\mathrm{HO}_{2}$ & $\mathrm{R} 11$ \\
\hline $\mathrm{CH}_{3} \mathrm{NO}_{3}+\mathrm{OH}$ & $\longrightarrow$ & $\mathrm{HCHO}+\mathrm{NO}_{2}$ & $\mathrm{R} 12$ \\
\hline $\mathrm{CH}_{3} \mathrm{NO}_{3}+h v$ & $\longrightarrow$ & $\mathrm{CH}_{3} \mathrm{O}+\mathrm{NO}_{2}$ & $\mathrm{R} 13$ \\
\hline $\mathrm{CH}_{3} \mathrm{OOH}+\mathrm{OH}$ & $\longrightarrow$ & $\mathrm{CH}_{3} \mathrm{O}_{2}$ & R14 \\
\hline $\mathrm{CH}_{3} \mathrm{OOH}+\mathrm{OH}$ & $\longrightarrow$ & $\mathrm{HCHO}+\mathrm{OH}$ & $\mathrm{R} 15$ \\
\hline $\mathrm{CH}_{3} \mathrm{OOH}+h v$ & $\longrightarrow$ & $\mathrm{CH}_{3} \mathrm{O}+\mathrm{OH}$ & R16 \\
\hline $\mathrm{CH}_{3} \mathrm{OH}+\mathrm{OH}$ & $\longrightarrow$ & $\mathrm{HCHO}+\mathrm{HO}_{2}$ & R17 \\
\hline $\mathrm{HCHO}+\mathrm{OH}$ & $\longrightarrow$ & $\mathrm{CO}+\mathrm{HO}_{2}$ & $\mathrm{R} 18$ \\
\hline $\mathrm{HCHO}+h v$ & $\longrightarrow$ & $\mathrm{CO}+\mathrm{HO}_{2}+\mathrm{HO}_{2}$ & $\mathrm{R} 19$ \\
\hline $\mathrm{HCHO}+h v$ & $\longrightarrow$ & $\mathrm{CO}+\mathrm{H} 2$ & R20 \\
\hline $\mathrm{HCHO}+\mathrm{NO}_{3}$ & $\longrightarrow$ & $\mathrm{CO}+\mathrm{HNO}_{3}+\mathrm{HO}_{2}$ & $\mathrm{R} 21$ \\
\hline
\end{tabular}

oxidation on the formation and loss of $\mathrm{OH}$ and $\mathrm{O}_{3}$ in the atmosphere. In principle, such an analytic approach to the determination of of the effects of individual VOC on the atmosphere is possible for any VOC. In practice, the very large number of possible reaction sequences for VOC other than $\mathrm{CH}_{4}$ makes this approach too complicated. Instead, incremental reactivity methods (e.g. Carter, 1994; Derwent et al., 1998) have been used to estimate the effects of higher-order VOC on ozone production, particularly in the context of urban photochemical smog. Using these methods, several runs of a photochemical model are performed, each with a slight perturbation to the amount of a particular target VOC. The change, or increment, in the amount of ozone produced by the model is then used to determine the incremental reactivity of each VOC under consideration. Disadvantages of the incremental reactivity approach compared with the sequence approach are that a model run must be performed for each individual $\mathrm{VOC}$ under consideration, and that the resulting incremental reactivities contain no information about the underlying mechanisms of ozone production (or removal) due to each VOC and all intermediate oxidation products.
In this paper a numerical implementation of the sequence method is presented, which, given a list of chemical reactions and their reaction rates, automatically traverses all degradation sequences for any given VOC, keeping track of radical and $\mathrm{NO}_{\mathrm{x}}$ conversions. This approach differs from the "history matrix" approach of Tonneson (1995) in that it analyses a single set of averaged or steady state reaction rates, rather than following the time steps of a time-dependant model simulation. It is shown how the output of this algorithm can be used to provide information on the effects of a target VOC on atmospheric budgets of radicals and $\mathrm{NO}_{\mathrm{x}}$. Applications of this information are discussed. This algorithm has already been applied in the literature to determine the yields of product species from isoprene (Taraborrelli et al., 2009), and the amount of radical recycling during isoprene oxidation (Lelieveld et al., 2008; Butler et al., 2008), although the algorithm itself was not described in this previous work. This paper provides the first detailed description and evaluation of the algorithm, and makes a sample implementation available as an electronic supplement: http://www.geosci-model-dev. net/2/145/2009/gmd-2-145-2009-supplement.zip. Section 2 describes the algorithm and its implementation, Sect. 3 describes our modelling approach, Sect. 4 evaluates the algorithm with some relatively simple chemical systems, Sect. 5 explores a potential application of the algorithm (calculation of ozone production potentials).

\section{Automating the sequence method}

The sequence algorithm is presented in pseudocode in Fig. 1. The basic idea behind the algorithm is to start at a "root species", and determine its oxidation products and the side effects of its oxidation reactions. Each of the oxidation products is then treated as an intermediate product for which the process is repeated.

The algorithm is recursive, and is initially called with the root species and the total rate of destruction of this root species as arguments. All rates of production and loss within the algorithm are specified in $\mathrm{mol} \mathrm{cm}^{-3} \mathrm{~s}^{-1}$. The first action performed is a check that the production rate of species as a fraction of the total rate of consumption of the root species is greater than min_rate. In this way, minor reaction sequences are not computed. The next step is the calculation of fraction, which represents the fraction of the total production of species traceable back to the root species at the current stage of the current sequence. The effective rates at the current stage of the current sequence of each of the reactions consuming species are the reaction rates from the model output multiplied by fraction. The contribution of each of these consumption reactions to each species on which the given reaction has an effect (the list of affected species is read from the array effect_list) is calculated based on these effective rates and the reaction stoichiometry (read from the array stoichiometry), and accumulated in the global variable 


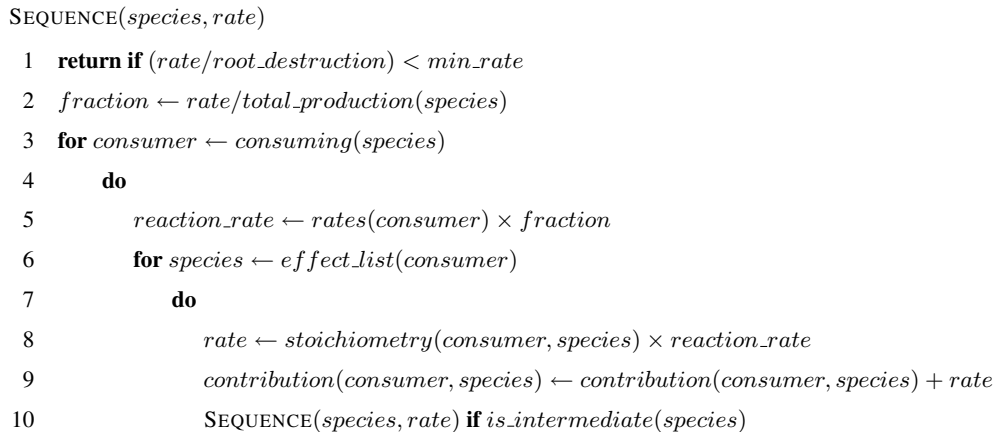

Fig. 1. Pseudocode description of the sequence algorithm.

contribution. Each of the products of the consumption reactions is itself the subject of a call to SEQUENCE if it is an intermediate product.

As the reaction sequence is followed through the recursive subroutine calls past more and more intermediate products, the rate gets progressively smaller. Recursion is terminated either when the sequence reaches its end, or when the rate falls below min_rate and the remainder of the sequence is ignored.

The algorithm makes use of a number of read-only global variables which must be initialised before the SEQUENCE subroutine is called.

- The rates array contains the rates of each reaction in the system, and is initialised from the output of a photochemical model.

- The totalproduction array contains an entry for each species consisting of the sum of any emissions and the rates of all chemical reactions which produce that species. This array is also initialised from the output of a photochemical model.

- root_destruction is a scalar variable containing the sum of the rates of all chemical reactions which consume the root species. This is initialised from model output.

- The consuming array contains an entry for each species comprising of a list of reactions which consume that species. This array is initialised from the specification of the chemical system used by the photochemical model.

- The effect_list and stoichiometry arrays, containing the list of reactants and products of each reaction and their stoichiometric coefficients, respectively, are also initialised from the chemical system specification.

- The is_intermediate array is a boolean array containing an entry for each species, which is true if the species is an intermediate product, and false otherwise. In order to compute all sequences of a complex chemical system, it is easier to specify as false which species are not intermediates (e.g. $\mathrm{OH}, \mathrm{HO}_{2}$, etc.), rather than to explicitly set all potential intermediate products to true. The true entries in this array may however be specified manually if the user is interested in computing only certain reaction sequences.

- min_fraction, as described above, is used to decide when the rate of the remainder of a sequence is small enough to be ignored. The value of this variable is specified by the user. When using the algorithm to analyse a chemical system, several runs should be performed using progressively smaller values of min_fraction as a test of the potential contribution of uncomputed sequences to the final result.

The algorithm does not count individual sequences, but rather integrates the effects of all significant sequences on all relevant species in the chemical system. The final result of the algorithm is stored in the global array contribution. For each species in the chemical system, the array contains a list of all reactions which contribute to the budget of that species, along with the rates of these contributions due ultimately to the oxidation of the root species. The nett effect of the oxidation of the root species on each of the other species in the system can be determined by summing the rates (positive for production, negative for loss) of the contributions to each species. When the chemical system is in steady state, the production and loss of the intermediate oxidation products of the root species (e.g. alkyl peroxy radicals) should approximately balance, there should be nett production of chain termination species (e.g. $\mathrm{CO}_{2}$ ) and there may be nett production or loss of radical and $\mathrm{NO}_{\mathrm{x}}$ species.

The performance of the algorithm is dependant on its implementation, the choice of minfraction, and also on the complexity of the chemical mechanism under analysis. An implementation of the SEQUENCE algorithm in the Perl 5 programming language, complete with self-contained input from the BASE model run (Sect. 3) is available in the electronic supplement http://www.geosci-model-dev.net/2/145/ 2009/gmd-2-145-2009-supplement.zip to this article. 


\section{Modelling approach}

To investigate the performance of the SEQUENCE algorithm, simulations are performed with the photochemical box model MECCA (Module Efficiently Calculating the Chemistry of the Atmosphere, Sander et al., 2005), which is based on a version of KPP (Kinetic Pre-Processor, Damian et al., 2002) modified to produce FORTRAN 90 code. All model runs in this study are performed using the near-explicit Master Chemical Mechanism (MCM) v3.1 (Saunders et al., 2003). The specification of the chemical reactions for the MCM was downloaded from http://mcm.leeds.ac.uk/MCM. Photolysis rates are parameterised as a function of solar zenith angle.

The atmospheric oxidation of $\mathrm{CH}_{4}$ to $\mathrm{CO}$ is chosen as the process used to validate the SEQUENCE algorithm. The reactions involved in this process are shown in Table 1. For clarity, only the reactions directly involved in transformation of $\mathrm{CH}_{4}$ and its oxidation intermediates to $\mathrm{CO}$ are shown. The MCM also includes explicit representations of other atmospheric processes such as the inorganic reactions involving $\mathrm{OH}, \mathrm{HO}_{2}, \mathrm{NO}_{\mathrm{x}}$ and $\mathrm{O}_{3}$, as well as near-explicit representations of the reactions of over 100 primary VOC and their oxidation products.

The model is run in a perpetual midday state, in which photolysis rates are kept constant at those calculated for local midday at $45^{\circ}$ latitude for the equinox. Mixing ratios of $\mathrm{CH}_{4}, \mathrm{CO}, \mathrm{O}_{3}$ and $\mathrm{NO}$ are held constant at $1.75 \mathrm{mmol} \mathrm{mol}^{-1}$, $200 \mathrm{nmol} \mathrm{mol}^{-1}, 40 \mathrm{nmol} \mathrm{mol}^{-1}$, and $100 \mathrm{pmol} \mathrm{mol}^{-1}$, respectively. Temperature is held constant at $293 \mathrm{~K}$, pressure at $101325 \mathrm{~Pa}$, relative humidity at $81 \%$, and all species are assumed to be well mixed up to an altitude of $1000 \mathrm{~m}$. Three different model simulations are performed. The BASE simulation contains only $\mathrm{CH}_{4}$ chemistry, with no deposition processes. The DEP simulation is the same as the BASE simulation but with deposition velocities for formaldehyde $(\mathrm{HCHO})$, methyl hydroperoxide $\left(\mathrm{CH}_{3} \mathrm{OOH}\right)$ and methyl nitrate $\left(\mathrm{CH}_{3} \mathrm{NO}_{3}\right)$ of $0.33 \mathrm{~cm} \mathrm{~s}^{-1}, 0.55 \mathrm{~cm} \mathrm{~s}^{-1}$, $1.1 \mathrm{~cm} \mathrm{~s}^{-1}$, respectively. The MIX simulation is the same as the BASE simulation, but includes constant emissions of $1 \times 10^{9} \mathrm{~mol} \mathrm{~cm}^{-2} \mathrm{~s}^{-1}$ of each of the non-halogenated primary VOC in the MCM (117 species in all, which are set to zero during the BASE and DEP runs). For all runs the model timestep is $20 \mathrm{~min}$, and a run time of $30 \mathrm{~d}$ is sufficient to ensure that all species are near steady state. Proximity to steady state is not a strict requirement of the SEQUENCE algorithm, but is desirable for validation purposes.

The SEQUENCE algorithm is run on output from the last timestep of each simulation. A value for the parameter minfraction of $1 \times 10^{-9}$ is sufficient to ensure that uncomputed reaction sequences do not significantly affect the output of the algorithm; a value of $1 \times 10^{-10}$ produces a change in the order of $0.001 \%$ in the results.

\section{Validation with $\mathrm{CH}_{4}$}

Despite being the simplest of the VOC, the MCM still requires 21 reactions to oxidise $\mathrm{CH}_{4}$ to $\mathrm{CO}$ (Table 1). There are many different possible sequences of different length through these 21 reactions, some of which potentially involve cycles (e.g. R9 followed by R10 followed by R9, etc.). At first the use of the SEQUENCE algorithm is demonstrated using a simpler case, the oxidation of $\mathrm{HCHO}$ to $\mathrm{CO}$. This process has four possible sequences (R18, R19, R20, and R21 from Table 1) each consisting of a single step. Using the output of the model at the last timestep of the BASE simulation, the SEQUENCE algorithm is run with $\mathrm{HCHO}$ as the root species. The output is summarised in Table 2. The algorithm correctly identifies the four sequences, and assigns rates to the contribution array which are equal to the rates of the reactions from the model. In this simple case, the SEQUENCE algorithm has not told us anything which could not have been learnt by simply inspecting the output of the model. It shows, however, that the algorithm provides a sensible result for this simple case.

The output of the SEQUENCE algorithm with $\mathrm{CH}_{4}$ specified as the root species (BASE simulation) is shown in Table 3. The CO yield of 0.9994 (rounded to 1 in Table 3), and the fact that the $\mathrm{CH}_{4}$ oxidation mechanism listed in Table 1 is carbon conserving shows us that the algorithm is correctly following the reaction sequences leading from $\mathrm{CH}_{4}$ to $\mathrm{CO}$. The algorithm does not explicitly give the sequences as lists of reactions, but an idea of the relative importance of various sequences in the oxidation of $\mathrm{CH}_{4}$ can be obtained by inspection of Table 3. For example, most $\mathrm{CH}_{3} \mathrm{O}_{2}$ is lost by reaction with $\mathrm{NO}$ in Reaction (R2), with the majority of the remainder reacting with $\mathrm{HO}_{2}$ via Reaction (R5) to form $\mathrm{CH}_{3} \mathrm{OOH}$, and a smaller amount reacting with the general pool of organic peroxy $\left(\mathrm{RO}_{2}\right)$ radicals (which in the BASE model run consists only of the methyl peroxy radical, $\mathrm{CH}_{3} \mathrm{O}_{2}$ ) via $\mathrm{Re}$ actions (R6), (R7), and (R8). Most HCHO is formed by decomposition of the alkoxy radical $\mathrm{CH}_{3} \mathrm{O}$. This process also forms approximately half of the $\mathrm{HO}_{2}$, the other half coming from $\mathrm{HCHO}$ photolysis. The magnitude of the (R9)-(R10) cycle can also be seen. There is a small amount of $\mathrm{OH}$ regeneration through photolysis of $\mathrm{CH}_{3} \mathrm{OOH}$.

As $\mathrm{CH}_{4}$ is the only VOC present in this model run, Table 3 can be reproduced by simply substituting the reaction rate output of the model for the output of the SEQUENCE algorithm. The result (not shown) is an exact copy of Table 3, again confirming that the SEQUENCE algorithm has found the correct sequences. A summary of the nett effect of $\mathrm{CH}_{4}$ oxidation is shown at the bottom line of Table 3 . The oxidation of one mole of $\mathrm{CH}_{4}$ produces one mole of $\mathrm{CO}$ and $0.26 \mathrm{~mol}$ of $\mathrm{H}_{2}$. Along the way, $1.7 \mathrm{~mol}$ of $\mathrm{OH}$ are converted to $1.7 \mathrm{~mol}$ of $\mathrm{HO}_{2}$, and $0.93 \mathrm{~mol}$ of $\mathrm{NO}$ are converted to $0.93 \mathrm{~mol}$ of $\mathrm{NO}_{2}$. In principle, in a steady-state system with no loss of intermediate products, the nett effect of $\mathrm{CH}_{4}$ oxidation on the intermediate species $\left(\mathrm{CH}_{3} \mathrm{O}_{2}, \mathrm{HCHO}\right.$, etc. $)$ 
Table 2. The output of the SEQUENCE algorithm using $\mathrm{HCHO}$ as the root species. The numbers in the table are rates in molecules $\mathrm{cm}^{-3} \mathrm{~s}^{-1}$.

\begin{tabular}{crrrrrrrr}
\hline & $\mathrm{HCHO}$ & \multicolumn{1}{c}{$h v$} & $\mathrm{OH}$ & $\mathrm{NO}_{3}$ & $\mathrm{HO}_{2}$ & $\mathrm{HNO}_{3}$ & $\mathrm{H}_{2}$ & $\mathrm{CO}$ \\
\hline $\mathrm{R} 18$ & $-1.2 \mathrm{e}+06$ & - & $-1.2 \mathrm{e}+06$ & - & $1.2 \mathrm{e}+06$ & - & - & $1.2 \mathrm{e}+06$ \\
$\mathrm{R} 19$ & $-3.3 \mathrm{e}+05$ & $-3.3 \mathrm{e}+05$ & - & - & $6.6 \mathrm{e}+05$ & - & - & $3.3 \mathrm{e}+05$ \\
$\mathrm{R} 20$ & $-5.6 \mathrm{e}+05$ & $-5.6 \mathrm{e}+05$ & - & - & - & - & $5.6 \mathrm{e}+05$ & $5.6 \mathrm{e}+05$ \\
$\mathrm{R} 21$ & -12 & - & - & -12 & 12 & 12 & - & 12 \\
Nett effect & $-2.1 \mathrm{e}+06$ & $-8.9 \mathrm{e}+05$ & $-1.2 \mathrm{e}+06$ & -12 & $1.9 \mathrm{e}+06$ & 12 & $5.6 \mathrm{e}+05$ & $2.1 \mathrm{e}+06$ \\
Normalised effect & -1 & -0.42 & -0.58 & $-5.7 \mathrm{e}-06$ & 0.89 & $5.7 \mathrm{e}-06$ & 0.26 & 1 \\
\hline
\end{tabular}

Table 3. The output of the SEQUENCE algorithm for $\mathrm{CH}_{4}$ in the BASE run. All rates have been normalised to the loss rate of $\mathrm{CH}_{4}$.

\begin{tabular}{|c|c|c|c|c|c|c|c|c|c|c|c|c|c|c|c|c|c|}
\hline & $\mathrm{CH}_{4}$ & $\mathrm{OH}$ & $\mathrm{HO}_{2}$ & $h v$ & $\mathrm{CH}_{3} \mathrm{O}_{2}$ & $\mathrm{CH}_{3} \mathrm{O}$ & $\mathrm{CH}_{3} \mathrm{OOH}$ & $\mathrm{CH}_{3} \mathrm{OH}$ & $\mathrm{HCHO}$ & $\mathrm{CH}_{3} \mathrm{NO}_{3}$ & $\mathrm{CH}_{3} \mathrm{O}_{2} \mathrm{NO}_{2}$ & NO & $\mathrm{NO}_{2}$ & $\mathrm{NO}_{3}$ & $\mathrm{HNO}_{3}$ & $\mathrm{H}_{2}$ & $\mathrm{CO}$ \\
\hline R1 & -1 & -1 & - & - & 1 & - & - & - & - & - & - & - & - & - & - & - & - \\
\hline R2 & - & - & - & - & -0.93 & 0.93 & - & - & - & - & - & -0.93 & 0.93 & - & - & - & - \\
\hline R3 & - & - & - & - & -0.00093 & - & - & - & - & 0.00093 & - & -0.00093 & - & - & - & - & - \\
\hline R4 & - & - & - & - & $-8.2 \mathrm{e}-05$ & $8.2 \mathrm{e}-05$ & - & - & - & - & - & - & $8.2 \mathrm{e}-05$ & $-8.2 \mathrm{e}-05$ & - & - & - \\
\hline R5 & - & - & -0.16 & - & -0.16 & - & 0.16 & - & - & - & - & - & - & - & - & - & - \\
\hline R6 & - & - & - & - & -0.0019 & 0.0019 & - & - & - & - & - & - & - & - & - & - & - \\
\hline R7 & - & - & - & - & -0.0019 & - & - & - & 0.0019 & - & - & - & - & - & - & - & - \\
\hline $\mathrm{R} 8$ & - & - & - & - & -0.0019 & - & - & 0.0019 & - & - & - & - & - & - & - & - & - \\
\hline R9 & - & - & - & - & -1.4 & - & - & - & - & - & 1.4 & - & -1.4 & - & - & - & - \\
\hline R10 & - & - & - & - & 1.4 & - & - & - & - & - & -1.4 & - & 1.4 & - & - & - & - \\
\hline R11 & - & - & 0.94 & - & - & -0.94 & - & - & 0.94 & - & - & - & - & - & - & - & - \\
\hline R12 & - & -0.00077 & - & - & - & - & - & - & 0.00077 & -0.00077 & - & - & 0.00077 & - & - & - & - \\
\hline R13 & - & - & - & -0.00016 & - & 0.00016 & - & - & - & -0.00016 & - & - & 0.00016 & - & - & - & - \\
\hline R14 & - & -0.1 & - & - & 0.1 & - & -0.1 & - & - & - & - & - & - & - & - & - & - \\
\hline R15 & - & - & - & - & - & - & -0.052 & - & 0.052 & - & - & - & - & - & - & - & - \\
\hline R16 & - & 0.013 & - & -0.013 & - & 0.013 & -0.013 & - & - & - & - & - & - & - & - & - & - \\
\hline R17 & - & -0.0019 & 0.0019 & - & - & - & - & -0.0019 & 0.0019 & - & - & - & - & - & - & - & - \\
\hline R18 & - & -0.58 & 0.58 & - & - & - & - & - & -0.58 & - & - & - & - & - & - & - & 0.58 \\
\hline R19 & - & - & 0.31 & -0.15 & - & - & - & - & -0.15 & - & - & - & - & - & - & - & 0.15 \\
\hline R20 & - & - & - & -0.26 & - & - & - & - & -0.26 & - & - & - & - & - & - & 0.26 & 0.26 \\
\hline $\mathrm{R} 21$ & - & - & $5.7 \mathrm{e}-06$ & - & - & - & - & - & $-5.7 \mathrm{e}-06$ & - & - & - & - & $-5.7 \mathrm{e}-06$ & $5.7 \mathrm{e}-06$ & - & $5.7 \mathrm{e}-06$ \\
\hline Nett effect & -1 & -1.7 & 1.7 & -0.43 & $-6 e-05$ & $-6.3 e-05$ & -0.00048 & $-5.2 \mathrm{e}-06$ & 0.0014 & $9.5 \mathrm{e}-07$ & -0.00016 & -0.93 & 0.93 & $-8.7 \mathrm{e}-05$ & $5.7 \mathrm{e}-06$ & 0.26 & 1 \\
\hline
\end{tabular}

Table 4. The output of the SEQUENCE algorithm for $\mathrm{CH}_{4}$, in the DEP run, with deposition of intermediates. All rates have been normalised to the loss rate of $\mathrm{CH}_{4}$.

\begin{tabular}{|c|c|c|c|c|c|c|c|c|c|c|c|c|c|c|c|c|c|}
\hline & $\mathrm{CH}_{4}$ & $\mathrm{OH}$ & $\mathrm{HO}_{2}$ & $h v$ & $\mathrm{CH}_{3} \mathrm{O}_{2}$ & $\mathrm{CH}_{3} \mathrm{O}$ & $\mathrm{CH}_{3} \mathrm{OOH}$ & $\mathrm{CH}_{3} \mathrm{OH}$ & $\mathrm{HCHO}$ & $\mathrm{CH}_{3} \mathrm{NO}_{3}$ & $\mathrm{CH}_{3} \mathrm{O}_{2} \mathrm{NO}_{2}$ & NO & $\mathrm{NO}_{2}$ & $\mathrm{NO}_{3}$ & $\mathrm{HNO}_{3}$ & $\mathrm{H}_{2}$ & $\mathrm{CO}$ \\
\hline R1 & -1 & -1 & - & - & 1 & - & - & - & - & - & - & - & - & - & - & - & - \\
\hline R2 & - & - & - & - & -0.92 & 0.92 & - & - & - & - & - & -0.92 & 0.92 & - & - & - & - \\
\hline R3 & - & - & - & - & -0.00092 & - & - & - & - & 0.00092 & - & -0.00092 & - & - & - & - & - \\
\hline R4 & - & - & - & - & $-5.8 \mathrm{e}-05$ & $5.8 \mathrm{e}-05$ & - & - & - & - & - & - & $5.8 \mathrm{e}-05$ & $-5.8 \mathrm{e}-05$ & - & - & - \\
\hline R5 & - & - & -0.16 & - & -0.16 & - & 0.16 & - & - & - & - & - & - & - & - & - & - \\
\hline R6 & - & - & - & - & -0.0019 & 0.0019 & - & - & - & - & - & - & - & - & - & - & - \\
\hline R7 & - & - & - & - & -0.002 & - & - & - & 0.002 & - & - & - & - & - & - & - & - \\
\hline R8 & - & - & - & - & -0.002 & - & - & 0.002 & - & - & - & - & - & - & - & - & - \\
\hline R9 & - & - & - & - & -1.4 & - & - & - & - & - & 1.4 & - & -1.4 & - & - & - & - \\
\hline R10 & - & - & - & - & 1.4 & - & - & - & - & - & -1.4 & - & 1.4 & - & - & - & - \\
\hline R11 & - & - & 0.93 & - & - & -0.93 & - & - & 0.93 & - & - & - & - & - & - & - & - \\
\hline R12 & - & -0.0002 & - & - & - & - & - & - & 0.0002 & -0.0002 & - & - & 0.0002 & - & - & - & - \\
\hline R13 & - & - & - & $-4.2 \mathrm{e}-05$ & - & $4.2 \mathrm{e}-05$ & - & - & - & $-4.2 \mathrm{e}-05$ & - & - & $4.2 \mathrm{e}-05$ & - & - & - & - \\
\hline R14 & - & -0.089 & - & - & 0.089 & - & -0.089 & - & - & - & - & - & - & - & - & - & - \\
\hline R15 & - & - & - & - & - & - & -0.047 & - & 0.047 & - & - & - & - & - & - & - & - \\
\hline R16 & - & 0.012 & - & -0.012 & - & 0.012 & -0.012 & - & - & - & - & - & - & - & - & - & - \\
\hline R17 & - & -0.002 & 0.002 & - & - & - & - & -0.002 & 0.002 & - & - & - & - & - & - & - & - \\
\hline R18 & - & -0.55 & 0.55 & - & - & - & - & - & -0.55 & - & - & - & - & - & - & - & 0.55 \\
\hline R19 & - & - & 0.3 & -0.15 & - & - & - & - & -0.15 & - & - & - & - & - & - & - & 0.15 \\
\hline R20 & - & - & - & -0.26 & - & - & - & - & -0.26 & - & - & - & - & - & - & 0.26 & 0.26 \\
\hline R21 & - & - & $3.8 \mathrm{e}-06$ & - & - & - & - & - & $-3.8 \mathrm{e}-06$ & - & - & - & - & $-3.8 \mathrm{e}-06$ & $3.8 \mathrm{e}-06$ & - & $3.8 \mathrm{e}-06$ \\
\hline Normalised & -1 & -1.6 & 1.6 & -0.42 & 0.00016 & -0.00017 & 0.015 & $-6.9 \mathrm{e}-06$ & 0.025 & 0.00068 & -0.0003 & -0.92 & 0.92 & $-6.1 \mathrm{e}-05$ & $3.8 \mathrm{e}-06$ & 0.26 & 0.96 \\
\hline
\end{tabular}

should be zero. As seen in Table 3, this is not the case. The fact that Table 3 can be reproduced by simply substituting the reaction rate output from the photochemical model shows that these nonzero terms in Table 3 are not artifacts introduced by the SEQUENCE algorithm, but rather result directly from the output of the photochemical model. They could be due to minor deviations from steady state, or small numerical inaccuracies in the reaction rate output from the photochemical model. 
Table 5. The output of the SEQUENCE algorithm for $\mathrm{CH}_{4}$, in the MIX run, including 117 other VOC. All rates have been normalised to the loss rate of $\mathrm{CH}_{4}$.

\begin{tabular}{|c|c|c|c|c|c|c|c|c|c|c|c|c|c|c|c|c|c|}
\hline & $\mathrm{CH}_{4}$ & $\mathrm{OH}$ & $\mathrm{HO}_{2}$ & $h v$ & $\mathrm{CH}_{3} \mathrm{O}_{2}$ & $\mathrm{CH}_{3} \mathrm{O}$ & $\mathrm{CH}_{3} \mathrm{OOH}$ & $\mathrm{CH}_{3} \mathrm{OH}$ & $\mathrm{HCHO}$ & $\mathrm{CH}_{3} \mathrm{NO}_{3}$ & $\mathrm{CH}_{3} \mathrm{O}_{2} \mathrm{NO}_{2}$ & NO & $\mathrm{NO}_{2}$ & $\mathrm{NO}_{3}$ & $\mathrm{HNO}_{3}$ & $\mathrm{H}_{2}$ & $\mathrm{CO}$ \\
\hline R1 & -1 & -1 & - & - & 1 & - & - & - & - & - & - & - & - & - & - & - & - \\
\hline R2 & - & - & - & - & -0.92 & 0.92 & - & - & - & - & - & -0.92 & 0.92 & - & - & - & - \\
\hline R3 & - & - & - & - & -0.00093 & - & - & - & - & 0.00093 & - & -0.00093 & - & - & - & - & - \\
\hline R4 & - & - & - & - & $-6.5 \mathrm{e}-05$ & $6.5 e-05$ & - & - & - & - & - & - & $6.5 e-05$ & $-6.5 e-05$ & - & - & - \\
\hline R5 & - & - & -0.14 & - & -0.14 & - & 0.14 & - & - & - & - & - & - & - & - & - & - \\
\hline R6 & - & - & - & - & -0.0056 & 0.0056 & - & - & - & - & - & - & - & - & - & - & - \\
\hline R7 & - & - & - & - & -0.0057 & - & - & - & 0.0057 & - & - & - & - & - & - & - & - \\
\hline R8 & - & - & - & - & -0.0057 & - & - & 0.0057 & - & - & - & - & - & - & - & - & - \\
\hline R9 & - & - & - & - & -1.5 & - & - & - & - & - & 1.5 & - & -1.5 & - & - & - & - \\
\hline R10 & - & - & - & - & 1.5 & - & - & - & - & - & -1.5 & - & 1.5 & - & - & - & - \\
\hline R11 & - & - & 0.95 & - & - & -0.95 & - & - & 0.95 & - & - & - & - & - & - & - & - \\
\hline R12 & - & -0.00067 & - & - & - & - & - & - & 0.00067 & -0.00067 & - & - & 0.00067 & - & - & - & - \\
\hline R13 & - & - & - & -0.00025 & - & 0.00025 & - & - & - & -0.00025 & - & - & 0.00025 & - & - & - & - \\
\hline R14 & - & -0.077 & - & - & 0.077 & - & -0.077 & - & - & - & - & - & - & - & - & - & - \\
\hline R15 & - & - & - & - & - & - & -0.041 & - & 0.041 & - & - & - & - & - & - & - & - \\
\hline R16 & - & 0.017 & - & -0.017 & - & 0.017 & -0.017 & - & - & - & - & - & - & - & - & - & - \\
\hline R17 & - & -0.0056 & 0.0056 & - & - & - & - & -0.0056 & 0.0056 & - & - & - & - & - & - & - & - \\
\hline R18 & - & -0.44 & 0.44 & - & - & - & - & - & -0.44 & - & - & - & - & - & - & - & 0.44 \\
\hline R19 & - & - & 0.41 & -0.21 & - & - & - & - & -0.21 & - & - & - & - & - & - & - & 0.21 \\
\hline R20 & - & - & - & -0.35 & - & - & - & - & -0.35 & - & - & - & - & - & - & 0.35 & 0.35 \\
\hline R21 & - & - & $6.3 e-06$ & - & - & - & - & - & $-6.3 e-06$ & - & - & - & - & $-6.3 e-06$ & $6.3 e-06$ & - & $6.3 e-06$ \\
\hline Normalised & -1 & -1.5 & 1.7 & -0.57 & $-4.6 e-05$ & $-4.7 \mathrm{e}-05$ & -0.00018 & $2.4 \mathrm{e}-05$ & 0.0013 & $9.2 \mathrm{e}-06$ & $-8.1 \mathrm{e}-05$ & -0.93 & 0.93 & $-7.1 \mathrm{e}-05$ & $6.3 e-06$ & 0.35 & 1 \\
\hline
\end{tabular}

The output of the SEQUENCE algorithm from the DEP run with $\mathrm{CH}_{4}$ as the root species is shown in Table 4. With deposition of intermediates, the yield of $\mathrm{CO}$ from $\mathrm{CH}_{4}$ oxidation is no longer 1 , but rather 0.96 . For each mol of $\mathrm{CH}_{4}$ oxidised, $0.04 \mathrm{~mol}$ of carbon are lost via deposition. It can be seen at the bottom line of Table 4 that the residual production of the three deposited species $\left(\mathrm{HCHO}, \mathrm{CH}_{3} \mathrm{OOH}\right.$, and $\mathrm{CH}_{3} \mathrm{NO}_{3}$ ) has changed from a small fraction of the total production (as seen in Tables 3 and 5) to a significant fraction of the total production of each of those intermediate species. This is because the SEQUENCE algorithm does not explicitly follow deposition as part of reaction sequences. Any molecules which are deposited are subsequently unavailable to continue reacting in the chemical system. The chemical production rate of deposited species is larger than their chemical loss rate. This is reflected in the rate output of the chemical model, and subsequently also in the rates array used by the SEQUENCE algorithm (Sect. 2).

The SEQUENCE algorithm is also capable of correctly following reaction sequences when the intermediate species have other production mechanisms. This is illustrated by analysis of the MIX run, which includes emissions of all nonhalogenated primary VOC in the MCM (Sect. 3). All of these species share common intermediates with $\mathrm{CH}_{4}\left(\mathrm{CH}_{3} \mathrm{O}_{2}\right.$, $\mathrm{HCHO}$, etc.), and most of the carbon which they contain ultimately forms $\mathrm{CO}$. The total chemical production rate of $\mathrm{CO}$ from this new run increases by 2.2 times compared with the BASE run. It is therefore no longer possible to duplicate the output of the SEQUENCE algorithm solely from inspection of the photochemical model output. If this were to be done, then the total production of $\mathrm{CO}$ would be greater than the total consumption of $\mathrm{CH}_{4}$. The output of the SEQUENCE algorithm from the MIX run with $\mathrm{CH}_{4}$ specified as the root species is shown in Table 5. The CO yield is still 1, indicating that the algorithm is capable of differentiating between
$\mathrm{CO}$ produced due to oxidation of $\mathrm{CH}_{4}$, and $\mathrm{CO}$ produced from oxidation of all other species.

The addition of the other VOC to the model in the MIX run has the effect of reducing the modelled $\mathrm{OH}$ concentration by about $40 \%$, and increasing the total concentration of organic peroxy radicals $\left(\mathrm{RO}_{2}\right)$ by about threefold. This changed chemical environment has led to changes in the $\mathrm{CH}_{4}$ oxidation sequences, which are visible in Table 5. The lower concentration of $\mathrm{OH}$ has led to a greater importance for photolysis reactions, in particular for $\mathrm{HCHO}$. In the BASE run, $58 \%$ of $\mathrm{HCHO}$ was removed by $\mathrm{OH}$, in this run that amount has decreased to $44 \%$. The threefold increase in $\mathrm{RO}_{2}$ concentration is noticeable in the approximate threefold increases in the contribution of $\mathrm{RO}_{2}$ reactions (Reactions $\mathrm{R} 6, \mathrm{R} 7$, and $\mathrm{R} 8$ ) to the loss of $\mathrm{CH}_{3} \mathrm{O}_{2}$. This extra competition from $\mathrm{RO}_{2}$ leads to a smaller contribution from $\mathrm{NO}$ to the removal of $\mathrm{CH}_{3} \mathrm{O}_{2}$ (Reaction R2), and thus also to a slightly reduced total yield of $\mathrm{NO}_{2}$ from $\mathrm{CH}_{4}$ oxidation compared with the BASE run.

\section{Application to ozone production potential}

The amount of $\mathrm{NO}_{2}$ produced during the atmospheric oxidation of VOC is closely related to the amount of $\mathrm{O}_{3}$ which can be formed (Sect. 1). The current state of the art for the determination of ozone production potentials of VOC is the use of incremental reactivity methods (Sect. 1), which do not explicitly account for this production of $\mathrm{NO}_{2}$, but rather relate incremental changes in $\mathrm{O}_{3}$ to incremental changes in VOC. By allowing the computation of $\mathrm{NO}_{2}$ yields from $\mathrm{VOC}$ oxidation, the SEQUENCE algorithm potentially represents an alternative method for the calculation of ozone production potentials of VOC.

The $\mathrm{NO}_{2}$ yields from the oxidation of the emitted VOC in the MIX run (Sect. 3) are shown in Fig. 2. As for $\mathrm{CH}_{4}$ 


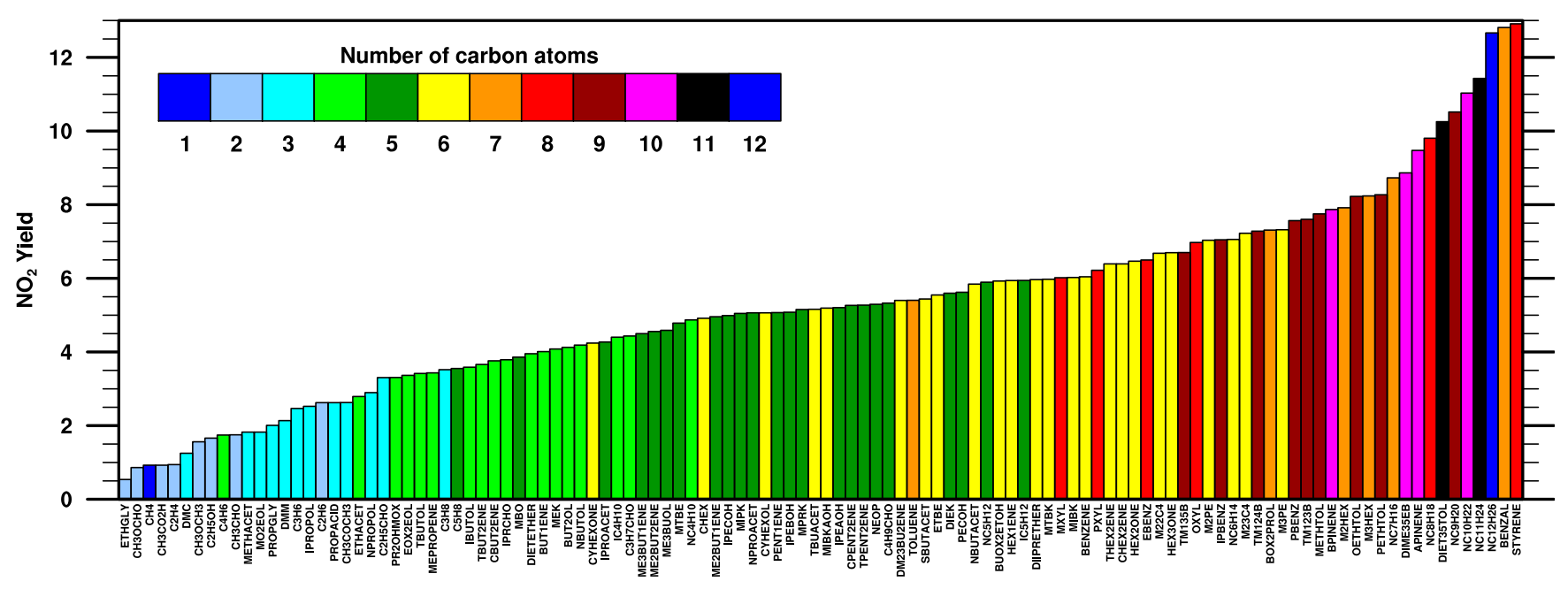

Fig. 2. The $\mathrm{NO}_{2}$ yields from oxidation of emitted VOC species. Bars are coloured according to the number of carbon atoms in each species. Only species with a yield of more than $0.5 \mathrm{~mol}$ of $\mathrm{NO}_{2}$ are shown.

(Table 3), most of the $\mathrm{NO}_{2}$ produced during the oxidation of other VOC is formed from reaction of $\mathrm{RO}_{2}$ with $\mathrm{NO}$. Larger VOC molecules can potentially produce more $\mathrm{RO}_{2}$ fragments during their oxidation chain than smaller molecules. The ozone production potential is thus expected to be higher for larger molecules. To illustrate the relationship between molecular size and $\mathrm{NO}_{2}$ production, the bars representing the emitted VOC in Fig. 2 have been coloured according to the number of carbon atoms in the molecule. In general, larger molecules produce more $\mathrm{NO}_{2}$ during their oxidation than smaller molecules, but there are exceptions. For example, ethylene glycol produces about half as much ozone as methane despite having twice as many carbon atoms, and benzaldehyde and styrene, despite having only seven and eight carbon atoms, respectively, produce more $\mathrm{NO}_{2}$ during their oxidation than n-dodecane, which has twelve carbon atoms. Other factors such as molecular structure and functionality clearly influence the production potential of $\mathrm{NO}_{2}$, and thus also of $\mathrm{O}_{3}$. The SEQUENCE algorithm provides a method with which to understand the mechanistic differences between ozone production potentials of various VOC by providing information about the contribution of individual reactions to the overall yield of products from those VOC (e.g. Table 3).

A full application of the SEQUENCE algorithm to the determination of ozone production potentials of all VOC in the MIX run under realistic scenarios is beyond the scope of this paper. Such a determination must take into account the variability of chemical regimes in the real world, the different timescales involved in the oxidation of these VOC, and the indirect role of $\mathrm{HO}_{2}$ radicals in the production of $\mathrm{NO}_{2}$, among other factors. A manuscript examining the ozone production potentials of these VOC is currently in preparation.

\section{Discussion and conclusions}

Sequential analysis of atmospheric oxidation pathways has been a part of the scientific literature for several decades, but has until now been performed "by hand". Its application was therefore limited to simple cases such as the oxidation of $\mathrm{CH}_{4}$. This paper presents the first detailed description and evaluation of the SEQUENCE algorithm, which is capable of extending the sequential analysis concept to oxidation systems with arbitrary levels of complexity, such as VOC oxidation in the state of the art near-explicit MCM. The output of the algorithm for each VOC is a matrix showing the effects of all reactions involved in the oxidation of that VOC on all chemical species involved in that oxidation.

The correctness of the algorithm has been verified for the simplest of cases, the oxidation of $\mathrm{HCHO}$ to $\mathrm{CO}$, and it has been shown that this also extends to the oxidation of $\mathrm{CH}_{4}$. It has also been shown that the algorithm can distinguish between the effects of individual VOC present in mixtures, calculating product yields, $\mathrm{OH}$ regeneration efficiencies, and $\mathrm{NO}_{2}$ yields. Results for many of the VOC in the MCM have been presented. A potentially interesting application of the SEQUENCE algorithm is the calculation of ozone production potentials of VOC. Work is currently underway exploring the potential of the algorithm for this application.

Acknowledgements. The author wishes to thank Mark Lawrence and Rolf'Sander for valuable discussions during the preparation of this manuscript. This work has been partly supported by the MEGAPOLI project. The research leading to these results has received funding from the European Community's Seventh Framework Programme FP/2007-2011 under grant agreement no. 212520.

The service charges for this open access publication have been covered by the Max Planck Society. 
Edited by: V. Grewe

\section{References}

Butler, T. M., Taraborrelli, D., Brühl, C., Fischer, H., Harder, H., Martinez, M., Williams, J., Lawrence, M. G., and Lelieveld, J.: Improved simulation of isoprene oxidation chemistry with the ECHAM5/MESSy chemistry-climate model: lessons from the GABRIEL airborne field campaign, Atmos. Chem. Phys., 8, 4529-4546, 2008,

http://www.atmos-chem-phys.net/8/4529/2008/.

Carter, W.: Development of ozone reactivity scales for volatile organic compounds, J. Air Waste Manage., 44, 881-899, 1994.

Crutzen, P.: A discussion of the chemistry of some minor constituents in the stratosphere and troposphere, Pure Appl. Geophys., 106, 1385-1399, 1973.

Damian, V., Sandu, A., Damian, M., Potra, F., and Carmichael, G.: The kinetic preprocessor KPP - a software environment for solving chemical kinetics, Comput. Chem. Eng., 26, 1567-1579, 2002.

Derwent, R., Jenkin, M., Saunders, S., and Pilling, M.: Photochemical ozone creation potentials for organic compounds in northwest Europe calculated with a master chemical mechanism, Atmos. Environ., 32, 2429-2441, 1998.

Johnston, H. and Kinnison, D.: Methane photooxidation in the atmosphere: Contrast between two methods of analysis, J. Geophys. Res., 103, 21967-21984, 1998.
Lehmann, R.: An algorithm for the determination of all significant pathways in chemical reaction systems, J. Atmos. Chem., 47, 45-78, 2004.

Lelieveld, J., Butler, T. M., Crowley, J. N., Dillon, T. J., Fischer, H., Ganzeveld, L., Harder, H., Lawrence, M. G., Martinez, M., Taraborrelli, D., and Williams, J.: Atmospheric oxidation capacity sustained by a tropical forest, Nature, 452, 737740, doi:10.1038/nature06870, 2008.

Sander, R., Kerkweg, A., Jöckel, P., and Lelieveld, J.: Technical note: The new comprehensive atmospheric chemistry module MECCA, Atmos. Chem. Phys., 5, 445-450, 2005, http://www.atmos-chem-phys.net/5/445/2005/.

Saunders, S. M., Jenkin, M. E., Derwent, R. G., and Pilling, M. J.: Protocol for the development of the Master Chemical Mechanism, MCM v3 (Part A): tropospheric degradation of nonaromatic volatile organic compounds, Atmos. Chem. Phys., 3, 161-180, 2003, http://www.atmos-chem-phys.net/3/161/2003/.

Taraborrelli, D., Lawrence, M. G., Butler, T. M., Sander, R., and Lelieveld, J.: Mainz Isoprene Mechanism 2 (MIM2): an isoprene oxidation mechanism for regional and global atmospheric modelling, Atmos. Chem. Phys., 9, 2751-2777, 2009, http://www.atmos-chem-phys.net/9/2751/2009/.

Tonneson, S.: Development and application of a process analysis method for photochemical oxidant models, Ph.D. thesis, University of North Carolina at Chapel Hill, 1995. 